\title{
Understanding the Energy Transition
}




\section{About KAPSARC}

The King Abdullah Petroleum Studies and Research Center (KAPSARC) is a non-profit global institution dedicated to independent research into energy economics, policy, technology and the environment, across all types of energy. KAPSARC's mandate is to advance the understanding of energy challenges and opportunities facing the world today and tomorrow, through unbiased, independent, and high-caliber research for the benefit of society. KAPSARC is located in Riyadh, Saudi Arabia.

\section{Legal Notice}

(C) Copyright 2018 King Abdullah Petroleum Studies and Research Center (KAPSARC). No portion of this document may be reproduced or utilized without the proper attribution to KAPSARC. 


\section{Key Points}

he world of energy is always undergoing transition, but the nature of the current phase of the transition is subject to a wide spectrum of interpretations that are often colored by bias and aspirations for a particular future end-point. In its simplest form, the energy transition is characterized by changes in the global fuel mix, the rapid growth in renewable energy, emerging new transportation patterns and the rapid implementation of new energy technologies. The drive for energy decarbonization is often perceived to underpin all these changes, but in many cases decarbonization is just a result of an ongoing trajectory led by technological innovation. In response to this transition, resource holders have renewed their efforts to adopt new strategies, while in consuming countries energy companies and the financial sector realign to a new reality. Is the energy transition going according to plan and how will the world of energy look in future years?

The energy transition is being driven by the interplay of increasingly complex dynamics, making it hard to predict future trajectories. This could lead to the risk of a disorderly transition characterized by increased price volatility, impacting the global oil market in particular.

De-carbonizing the entire value chain is proving to be a major challenge; the carbon footprint of many clean technologies is simply being transferred to other elements of the chain.

Some new technologies such as electric vehicles fail to deliver the lower net emissions and fuel savings originally expected.

As electricity consumption grows, the power sector fuel mix becomes a key battleground for competing fuels, with exposure to electricity - the key element for achieving decarbonization targets - becoming a major risk.

Governments are increasingly being joined by the private sector in the drive to decarbonization.

The drivers for global energy demand growth remain firmly centered on China and India. There could be a range of unexpected global consequences if their economies stutter.

Low-cost legacy oil producers are well-placed to benefit from short-term price volatility, while investing in measures to retain value across the hydrocarbon chain gives them an opportunity for a sustainable economic future. 


\section{Executive Summary}

B arely a few years since the phrase 'energy transition' entered the mainstream lexicon, it is becoming clear that conventional economic models are inadequate for deconstructing the complexity surrounding the future trajectory of global energy, the impacts of decarbonization and the required response by governments and corporations. KAPSARC's energy workshop series aims to provide insights by bringing together a range of experts from government, the private sector and academia.

Energy scenarios published by a wide range of organizations including, inter-alia, the International Energy Agency (IEA), OPEC, the World Energy Council and BP reflect the complexity of the energy transition and the multiplicity of possible outcomes and impacts. As awareness of the complexity of the energy transition increases, many scenarios are raising the number of possible pathways, a phenomenon that serves to reduce, rather than increase, clarity.

Research recently undertaken suggests that some of the drivers of the transition, hitherto regarded as key, might not be as powerful as originally anticipated, either in terms of accelerating the transition or in decarbonizing the fuel mix. A case in point is electric vehicles (EVs) that, irrespective of the speed of uptake, are now viewed as having a heavy lifecycle carbon footprint and resulting in a relatively low net displacement of oil. A fleet of 100 million EVs would reduce oil demand growth by less than 2 million barrels per day (bbl/d). Continued improvements in the fuel efficiency of the internal combustion engine (ICE), allied with hybrid technologies, could extend the life of traditional ICE vehicles. Potentially more disruptive trends in oil demand for transportation include the increased use of natural gas as a fuel in shipping and trucking, and consumers opting out of car ownership altogether.
The power sector will be the key battleground in an emerging inter-fuel war. Renewables will increasingly meet the growing demand for electricity across the globe, with natural gas continuing to offer flexibility despite limited decarbonization benefits. Exposure to electricity becomes a major risk at the generation or load ends of the chain. Coal remains firmly entrenched even if its market share falls. Much will depend on the desire of policymakers in key consuming countries such as India and China to cut back on current plans to build new coal-fired plants or even to retire existing units.

India is expected to overtake China as the main driver for primary energy demand growth. There is a risk that an economic downturn in either India or China could have a major impact on global demand growth, as most of it comes from these two countries.

Changing demand patterns for some petroleum products, notably diesel, could require a major reconfiguration in the global refining industry. Diesel is under pressure in multiple markets for many reasons: in Europe due to particulate emissions; in India due to the electrification of railways; in distributed power generation from the expansion of power grids; in trucks from electricity and liquefied natural gas (LNG); and in passenger vehicles from electricity and potentially hydrogen.

The changing fuel mix, especially in transportation, will raise fiscal challenges in countries that rely on oil consumption taxes and in countries that are resource holders. Many of the latter are already pursuing strategies to diversify their economies while at the same working to secure a sustainable market for their resources.

Meanwhile, in the short to medium term, there is a risk of a disorderly transition caused by disrupted 
markets and price volatility, as corporations and financial markets weigh up the perceived investment risk in the hydrocarbons sectors and delay supporting necessary investments in maintaining production capacity. Low-cost legacy oil producers, such as those in the Gulf Cooperation Council (GCC) that are prepared to continue investing, are expected to reap windfall revenue that they could reinvest in securing a sustainable future for their economies. 


\section{Background to the Workshop}

D uring 2017, KAPSARC launched a new research initiative focused on the role of fossil fuels, particularly petroleum, as the world transitions to a low carbon future after the Paris Agreement. As part of the initiative, a joint workshop with the International Energy Forum (IEF) took place in February, 2017, followed by a twoday workshop in The Hague from April 19-20, 2017 with the Clingendael International Energy Program (CIEP). KAPSARC and the IEF held subsequent workshops in Riyadh on December 11, 2017 and February 15, 2018.

Over the past two years, many of the world's leading energy think tanks have launched programs looking at the energy transition. These initiatives bring different perspectives, including considering the future of oil, the challenge for policymakers, threats to corporate business models, and the preparedness of individual states to adapt to the transition and their ability to limit the potential for economic damage. The two most recent workshops, hosted by KAPSARC and the IEF, brought some of these institutions, along with a range of academics, to the table for a discussion on the potential global economic implications posed by the energy transition.

This discussion, often colored by unintended bias, is where energy, decarbonization and the climate debate meet. By bringing together a wide range of experts, these two workshops attempted to provide a degree of clarity to the discussion as to how the future energy landscape will look.

Key questions asked of the participants were:

Decarbonization policy or technological progress: What is driving the energy transition?

The energy transition: Is it just about the future energy mix?

What is the future for relatively clean energy sources such as gas, nuclear and hydrogen?

How will countries mitigate risks associated with the energy transition?

Will changing demand patterns affect geopolitical relationships? 


\section{Understanding the Energy Transition: Putting Scenarios into Context}

vidence that the world is in the opening phase of another profound energy transition is incontrovertible, but doubts persist as to both its speed and its depth. There is particular uncertainty regarding the future of oil in an evolving energy mix, with scenarios giving mixed messages. Changing demand patterns, questions over the net decarbonization rate associated with competing fuels, evolving policy frameworks and the pace of technological change all contribute to an uncertain trajectory for global energy.

This uncertainty is reflected in, and exacerbated by, the nature and the proliferation of energy scenarios. Institutions that regularly publish long-range energy scenarios now typically offer three, and in some cases four, potential future pathways. The resulting range of anticipated outcomes, notably future oil demand, is so large that it offers very few insights beyond the fact anything might happen.

Bipolar views of the future energy landscape are increasingly emerging: one in which clean transportation, notably electric vehicles (EVs) fueled by renewable energy, drives oil into the recesses of history, and another in which gas takes center stage, offering a cleaner fuel mix both in transportation and power generation. In most base case scenarios, oil retains a place as a transportation solution particularly freight and aviation - in the medium term, backed by continued demand from the chemicals sector.

The bipolarity of views is a natural result of the range of methodologies used, which inevitably color the scenarios. Traditional models used by organizations such as the IEA and OPEC are based on historical relationships that tend to miss potentially disruptive trends; new models look for disruptive trends such as EVs and try to work backward, and climate-based models look at required targets and work backward. Overall, scenarios tend to focus on transportation, but there is a clear need to look at the entire energy value chain, especially if one wants to understand carbon impacts and decarbonization strategies.

Existing real-world situations already hint at the future. To be sure, global demand for bunker fuel is falling, while natural gas is replacing diesel as the fuel of choice in energy-intensive industries such as mining. But is the future so simple and unidirectional? 


\section{Transportation: A Major Battlefield but Not Where the War Will Be Won}

The penetration of EVs, the new and visible face of the energy transition, is likely to continue at a rapid rate, but a range of issues are emerging that could limit their transformative impact on the energy transition. A growing body of research suggests that life-cycle carbon emissions from EVs are not as impressive as first thought, while well-to-wheel overall system efficiency is not as great as first thought due to electricity transmission and battery charging losses. In particular, a study commissioned by the European Union suggests that EV life-cycle emission savings only start after 60,000 kilometers using existing battery technology.

Efforts by regulators to drive tighter fuel economy standards and incentivize the adoption of lightweight materials is creating a rearguard defense for traditional car manufacturers. Wildcards include regulatory discontinuities such as banning ICE cars from city centers, and changing consumer patterns such as lower car ownership and shared mobility. Indeed, the fall in vehicle owners in developed countries could have a greater combined effect than a rise in the number of EVs.

For its part, natural gas is looking to grab a bigger slice of the transportation pie. LNG is now a mainstream option in the shipping industry, while the evidence from the mining industry shows that it is a commercially attractive, as well as a relatively clean, option for commercial truck fleets. 


\section{Electricity: Who Will Win the War?}

Itimately, the dual battles over the future fuel mix and decarbonization intersect in the power generation business. Increasing global demand for electricity is one certainty that underpins all energy scenarios. Increasing per capita disposable income, rising demand for airconditioning and the growth in EVs all conspire to ensure the world will need more power.

Lower costs mean that renewable energy will take an increasing share of new power generation but, globally, natural gas is still perceived as the fuel of choice given its flexibility in dealing with seasonal demand peaks. Much hinges on the development of new technology. In South Australia, large-scale battery storage may provide a viable option to deal with daily volatility and issues of grid stability. However, in many countries with large seasonal variations in demand patterns, natural gas is likely to remain attractive as a flexible fuel for low-cost gas turbine generated reserves.

Coal remains remarkably resilient. Though demand is falling in developed countries, coal is deeply embedded in key markets such as China and India where the rapid growth in energy demand makes it hard to cut coal use for power generation. Between 2015-16, coal's share of the Indian power generation fuel mix fell from 58 percent to 57 percent, but overconsumption still rose from 397 to 412 million tonnes of oil equivalent. Overall, India has 65 gigawatts of new coal-fired capacity in the planning stage. By 2030 , Indian coal consumption is likely to rise by 50 percent from 800 million tonnes per annum (mtpa) to 1200 mtpa under a 'least coal' scenario. China, with its air quality concerns, is likely to continue reducing coal consumption growth but will struggle to achieve substantive cuts. 


\section{Regional Drivers and Decarbonization: India Moving into the Fast Lane?}

$\mathbf{H}$ ydrocarbon resource holders take comfort from the expectation that primary energy demand growth will continue albeit at a slowing rate, but more than enough to offset the decline in oil's share of the global energy mix. However, the overall size of the primary energy pie is increasingly coming under question. Primary energy demand grows in almost all scenarios despite slower growth of the world's population. But demand growth could be constrained by uncertain economic growth. All scenarios suggest continued steady growth across the global economy, but this is not a given. China is one of the main engines of global economic growth, but should China's growth stutter then one of the key assumptions underpinning most scenarios would collapse. Furthermore, future economic growth is likely to center on services rather than industry, and increasing energy efficiency is an added downside risk to continued demand for primary energy. Once again, China's intensifying focus on increased energy efficiency could cancel out the anticipated rise in primary energy demand.

India is anticipated by some to take over from China as the main engine for global energy demand growth. But as one looks into the future, the decarbonization issue quickly kicks in as a potential dampener of demand. For India, as with China, the curbing of greenhouse gas emissions is driven by air quality concerns. New Delhi has now overtaken Beijing as the world's most polluted capital city and policymakers, hitherto passive to air quality problems, are beginning to implement measures to reduce pollution while enhancing the resilience and reliability of the national grid.

In India, as in China, the biggest threat is to the middle of the barrel. Growing diesel demand from small, local power generation could collapse as the country expands and modernizes its grid, while demand from the rail sector is set to decline as the track system becomes fully electrified. Currently, half the track system is used by diesel locomotives. The decline in diesel demand is not limited to India and China. Its hitherto preeminent role as a fuel of choice in Western Europe is already under threat; the result of the Volkswagen 'dieselgate' scandal and a growing awareness of pollution caused by particulate emissions. In many markets, diesel vans and trucks are increasingly likely to be replaced by electric vans for 'last mile' delivery in urban centers. In China, increased bike use, helped by bike sharing, despite the problems with these services, resulted in 10 million journeys being undertaken on two wheels and has already led to a substantial cut in oil demand, with noticeable increases in average traffic speeds in large cities. Consumer trends as much as government policy will drive clean energy technology.

Diesel's potential decline in India highlights a global trend that is likely to require a reconfiguration of the world's refinery industry, which is also coming under pressure from an evolving mismatch between the crude grades of the supply and demand barrels. 


\section{Expect Increased Price Volatility but Opportunities emerge for the Middle East}

The investment community is already reacting to the fear, regardless of the reality, of peaking oil demand. Many funds, including Norway's sovereign fund, are divesting from oil. In response to perceptions of increased risk, the cost of capital is likely to increase, contributing to a lack of investment in new high-cost oil and arresting natural declines in existing fields. By 2030, the world will need more than 30 million $\mathrm{bbl} / \mathrm{d}$ of new oil just to replace declines in existing fields. New technologies are already attracting finance flows with higher expectations, and equity prices in the hydrocarbon sector are already falling. This trend is likely to be particularly acute in North America where shale oil decline rates are much higher than normal reserves and investment is still high. Lower investment could result in even greater oil production declines and price fluctuations. The downstream is already experiencing bearish sentiment, while investment in new refineries is at a historic low. Overall, the threat of supply could lead to a disorderly transition, potentially impacting oil price volatility.

In the long-term, legacy oil producers will need new economic models. Countries such as the Kingdom of Saudi Arabia and the United Arab Emirates have already established economic plans to reduce their dependency on oil export revenue. However, in the short term, these countries are likely to be the prime beneficiaries of the energy transition due to their willingness to continue investing to replace declines in their own fields and make good the loses of others. Saudi Arabia has invested \$100 billion in the last decade to maintain capacity and has indicated its willingness to invest whatever it takes to retain its position as one of the world's pre-eminent oil exporters. Other winners of the energy transition include China's photovoltaic (PV) manufacturing industry and its rare earths sector. 


\section{Surviving the Transition: How Nations Need to Adapt}

The energy transition poses challenges for governments across the spectrum as they struggle with the trade-off between achieving their climate change - or air quality - targets and managing their fiscal impacts. Energy is rarely fiscally neutral: governments either take rent from energy (resource holders and those that tax energy) or subsidize it. The energy transition and low energy prices offer the opportunity to reduce or end subsidies. Governments that tax some energy sources, notably petroleum products, while subsidizing or incentivizing clean energy are likely to be forced to face a fiscal realignment.

For their part, legacy resource holders are re-thinking their entire economic models and questioning the wisdom of historical export-focused and revenue-generating policies. Policymakers in Saudi Arabia, for example, are becoming increasingly aware that the current growth model has not delivered the Kingdom's full potential in terms of sustainable economic growth and, above all, employment. The energy transition is providing the opportunity for a strategic rethink about future development plans as illustrated by Saudi
Arabia's $\$ 200$ billion investment in solar PV with SoftBank. Even though existing non-oil economic growth models are dependent on cheap energy and imported labor, increases in the sector have led to a fall in the fiscal break-even point for oil. Saudi Arabia, as with other GCC states, continues to add value to its oil exports by expanding its petrochemicals production, even though it risks the threat of future carbon border adjustment taxes. Challenges facing the country include the need to further integrate its oil and gas sector with the wider economy, and to increase local content in the sector. There is scope to grow its average local content from the current level of 32 percent.

Russia considers itself to be in a stronger position than other oil exporters as it regards oil export revenue as a bonus rather than an indispensable source of government revenue. Over the last two decades, the country has used revenue from the hydrocarbons sector to diversify its economy and to strengthen its economic infrastructure. Among policymakers, the debate centers on gas utilization and the need to manage the trade-off between export revenue and domestic demand. 


\section{Decarbonization: It All Boils Down to Electricity}

D espite the perceived success of the Paris Agreement, no base-case scenario suggests the world will muster enough sufficiently robust nationally determined contributions to reach the 1.5 degree Celsius target for global warming since preindustrial times. This, however, neither negates the policy push for the energy transition nor the fact that continued efforts to decarbonize the sector will accelerate.

Two clear trends are emerging in the process of decarbonization. The first, alluded to earlier, is that the reduction in greenhouse gas (GHG) emissions in the developing world is driven primarily by air quality concerns rather than a desire to curb carbon emissions. As a result, policies tend to focus on areas that improve urban air quality rather than lower carbon emissions across the whole economy. The second is that the corporate sector and civil society increasingly drive the decarbonization process in developed economies. Large corporations are now setting self-regulative targets in anticipation of future requirements, a process mirrored in many cases by cities and municipalities.

The key challenge in achieving climate targets will be decarbonizing electricity. In developing countries, where major economic decisions are state-led, governments are likely to focus on clean energy sources such as renewables and natural gas for new power plants. The role of gas is likely to be hotly debated in countries that do not have indigenous resources, with cost and energy security issues at the forefront. In liberalized economies, markets are key to delivering decarbonization, and a mix of innovative solutions are expected to emerge. Large renewable energy projects offer economies of scale, but these can be complemented by networks of smaller rooftop PV panels, connected to a growing pool of batteries in cars and homes, that could one day become an interconnected grid. However, batteries alone will not provide storage to cover seasonal variations in demand, and market solutions will need to internalize the costs of long-term reliability to prevent overinvestment in technologies that 'farm the hidden rents.' For governments, the challenge will be to create enabling environments while resisting the urge to directly intervene before new market mechanisms have found their equilibria.

This current energy transition is running on multiple tracks and at different speeds, resulting in complex interactions and multiple feedback loops. How the future energy landscape will end up looking is less certain, particularly which fuels will play what roles in the energy mix. Whether the world will decarbonize sufficiently to slow down - let alone reverse - the process of climate change may still be an open question. Either way, there will be a role for hydrocarbons as there will still be applications that are cost-effective even after mitigating their GHG emissions. Future KAPSARC workshops will shed further light on this complex transition. 


\section{About the Workshop}

n 2017 and 2018, KAPSARC convened a series of workshops on the Role of Oil in the Low Carbon Energy Transition. The third and fourth events were held in Riyadh on December 11, 2017 and February 15, 2018, the latter in association with the International Energy Forum. The Workshops were held under a modified version of the Chatham House Rule under which participants consented to be listed below, having joined on one or both days. However, none of the content in this briefing can be attributed to any individual attendee.

\section{List of participants}

Mustafa Ansari - Analyst, Energy Research, Arab Petroleum Investments Corporation (APICORP)

Mohamed Saleh Abdulla Al Audhli - Analyst, Mubadala Petroleum and Petrochemicals

Jan Ban - Senior Research Analyst, OPEC

Partha Sarathi Bhattacharyya - former Chairman, Coal India Ltd.

Jason Bordoff - Director, Center on Global Energy Policy, Columbia University

Weidong Chen - President, Mind Institute

Joel Couse - Trading and Shipping Vice President, Market Analysis, Total

Brian Efird - Program Director, Policy and Decision Science, KAPSARC

Ramón Espinasa - General Coordinator, Extractive Sector Initiative, Infrastructure and Energy Sector, InterAmerican Development Bank

Antoine Halff - Director, Global Oil Markets, Columbia University

\section{David Hobbs - Head of Research, KAPSARC}

Amos Hochstein - VP and Senior Advisor, Tellurian, Former U.S. Special Envoy, International Energy Affairs

Maurizio La Noce - Senior Advisor, CEO Energy Office, Mubadala Petroleum and Petrochemicals
Chris Midgely - Global Director of Analytics, S\&P Global Platts

Tatiana Mitrova - Director, Energy Center, Skolkovo Business School

Paul Mollet - Research Fellow, KAPSARC

Majid Al Moneef - Secretary General, Kingdom of Saudi Arabia Supreme Economic Council

Ibrahim Muhanna - Advisor to the Minister, Ministry of Energy, Industry, and Mineral Resources (MEIM)

Aljawhara Al Quayid - Research Analyst, KAPSARC

Luis Bertrán Rafecas - Secretary General, International Gas Union

Shahd AIRashed - Research Associate, KAPSARC

Maxime Schenckery - Visiting Researcher, KAPSARC

Rami Shebaneh - Research Associate, KAPSARC

Masakazu Toyoda - Chairman and Chief Executive Officer, Institute of Energy Economics, Japan (IEEJ)

Christer Tryggestad - Senior Partner, Global Energy Perspectives, McKinsey and Company

Sergey Vakulenko - Head of Strategy, Gazprom Neft

Christof van Agt - Senior Energy Analyst, International Energy Forum (IEF)

Zhen Wang - Deputy Director-General, CNPC

Colin Ward - Research Fellow, KAPSARC

Jamie Webster - Senior Director, Center for Energy Impact, Boston Consulting Group

Zhixin Wen - Deputy Director, Department Global Resources and Exploration Planning, RIPED, CNPC

Kang Wu - Program Director, Markets and Industrial Development, KAPSARC

Sun Xiansheng - Secretary General, IEF 


\section{About the Team}

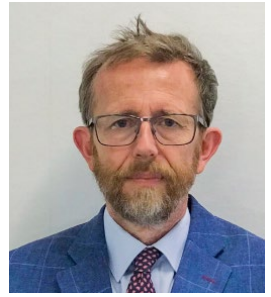

\section{Paul Mollet}

Paul Mollet is a former journalist and energy market analyst with almost thirty years of experience in international energy markets. He has lived and worked in London, Madrid, Dubai, Lisbon, Doha and Sweden. Previously, he was Middle East bureau chief for Platts and Petroleum Argus. 
INAPSARC

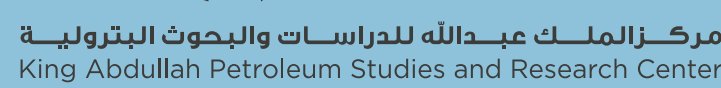

www.kapsarc.org 